\title{
KONDISI POPULASI DAN POLA PENYEBARAN ANGGREK Eria spp. DI RESORT BALIK BUKIT TAMAN NASIONAL BUKIT BARISAN SELATAN
}

\section{(THE CONDITION OF POPULATION AND DISTRIBUTION PATTERNS OF Eria spp. ORCHIDS AT BALIK BUKIT RESORT ON BUKIT BARISAN SELATAN NATIONAL PARK)}

\author{
Kurnia Albarkati ${ }^{1)}$, Indriyanto ${ }^{1)}$ dan Yusnita ${ }^{2)}$ \\ ${ }^{1)}$ Jurusan Kehutanan Fakultas Pertanian Universitas Lampung \\ ${ }^{2)}$ Jurusan Agroteknologi Fakultas Pertanian Universitas Lampung \\ Jl. Soemantri Brojonegoro No. 1 Bandar Lampung \\ Email : kurnia.albarkati09@gmail.com \\ Phone : 085768749699
}

\begin{abstract}
ABSTRAK
Kawasan hutan Resort Balik Bukit merupakan suatu kawasan yang diperuntukkan sebagai kawasan pelestarian alam yang memiliki kekayaan alam yang dapat dikembangkan. Kawasan tersebut merupakan bagian kawasan Taman Nasional Bukit Barisan Selatan yang memiliki beranekaragam jenis flora, termasuk di dalamnya terdapat berbagai jenis anggrek. Jenis anggrek yang ada di kawasan hutan tersebut lebih kurang 154 jenis (Lembaga Ilmu Pengetahuan Indonesia, 2011). Penelitian ini bertujuan untuk mengetahui kondisi populasi dan pola penyebaran anggrek Eria spp. Penelitian ini dilakukan pada bulan Agustus 2015. Metode yang digunakan adalah metode petak ganda secara sistematis dengan intensitas sampling (IS) $0,1 \%$. Ukuran tiap petak $20 \mathrm{~m}$ x $20 \mathrm{~m}$ dan luas total Resort Balik Bukit adalah 3.560 ha, sehingga jumlah seluruh petak sampel sebanyak 90 buah. Variabel yang diamati yaitu jenis anggrek, populasi dan pola penyebaran anggrek Eria spp. Berdasarkan hasil penelitian, populasi anggrek Eria spp. ditemukan sebanyak 10 jenis anggrek. Anggrek jenis Eria iridifolia ditemukan paling banyak sebesar 22,50 individu/ha dibanding jenis anggrek Eria lain. Diikuti oleh jenis E. erecta sebesar 14,72 individu/ha dan jenis E. flavescens sebesar 8,33 individu/ha. Sedangkan jenis lain yaitu E. discolor, E. javanica, E. junghunii, E. mucronata, E. oblitterata, E. retusa, E. robusta memiliki kerapatan sebesar 1-4 individu/ha. Kondisi pola penyebaran pada anggrek E. discolor, E. erecta, E. flavescens, E. iridifolia, E. javanica, E. mucronata, E. obletterata, dan E. retusa masuk kedalam kategori bergerombol. Sedangkan anggrek Eria junghunii masuk kedalam kategori seragam dan anggrek E. robusta masuk kedalam kategori acak.
\end{abstract}

Kata kunci: anggrek Eria spp., populasi, pola penyebaran

\begin{abstract}
Forest area of Balik Bukit Resort allocated as regions of natural preservation. This area has many potential/natural resources that could be developed. This area is located at Bukit Barisan Selatan National Park which have diverse types of flora, including various types of orchids. Approximately there were 154 typeof orchids in this area (Indonesia Institute of Sciences, 2011). This research aims were to know the population and distribution patterns of Eria spp orchids. This research was conducted in August 2015. The method used is the double plots systematically method with sampling intensity (SI) $0.1 \%$. The size of each swath of $20 \mathrm{~m}$ $x 20 \mathrm{~m}$ and the total area of the Balik Bukit Resort was 3,560 ha, so that the total number of sample plots were 90 units. The observed variables were types of Orchid, Orchid populations and patterns of spread of Eria spp. Based on the results of the study, there were 10 different
\end{abstract}


types of Eria spp.. Eria iridifolia found most of 22.50 individuals/ha compared to other types of orchids Eria. Followed by the type of E. erecta of 14.72 individuals/ha E. flavescens and type of 8.33 individuals/ha. Whereas other types is E. discolor, E. javanica, E. junghunii, E. mucronata, E. oblitterata, E. retusa, E. robusta has a density of $1-4$ individuals/ha. Distribution pattern of the orchids E. discolor, E. erecta, E. flavescens, E. iridifolia, E. javanica, E. mucronata, E. obletterata, and E. retusa enter into the category of a huddle. While the orchids E. junghunii belonging to the category of uniform and the orchids $E$. robusta into random categories.

Keywords: distribution pattern, Eria spp. orchids, population

\section{PENDAHULUAN}

Resort Balik Bukit merupakan salah satu kawasan yang berada di Taman Nasional Bukit Barisan Selatan yang memiliki beranekaragam jenis flora, termasuk di dalamnya terdapat berbagai jenis anggrek. Jenis anggrek yang ada di kawasan hutan tersebut lebih kurang 154 jenis (Lembaga Ilmu Pengetahuan Indonesia, 2011). Anggrek adalah tanaman hias anggota Orchidaceae, merupakan satu suku tumbuhan berbunga yang memiliki anggota atau jenis terbanyak. Jenisnya tersebar luas dari mulai wilayah tropika basah sampai lokasi sirkumpolar, walau sebagian besar ditemukan di wilayah tropis. Anggrek dapat bertahan di dalam area beriklim sedang pada situasi ketersediaan air yang rendah. Oleh karena itu, anggrek cenderung mempunyai organ-organ yang sukulen atau berdaging dengan kandungan air yang tinggi (Balai Besar Taman Nasional Bukit Barisan Selatan, 2009). Salah satu jenis anggrek yang terdapat di Resort Balik Bukit adalah anggrek Eria spp. Bunga dari marga ini cukup menarik dan mudah tumbuh dengan persyaratan lingkungan yang tidak terlalu sulit, mampu bertahan pada kondisi yang panas dan kelembapan tinggi serta tersebar mulai dari hutan dataran rendah, hutan mangrove, rawa, sampai dengan pegunungan dengan ketinggian tempat mencapai $2.400 \mathrm{~m}$ dpl (Lembaga Ilmu Pengetahuan Indonesia, 2011).

Tujuan penelitian ini adalah untuk mengetahui kondisi populasi dan pola penyebaran anggrek Eria spp. di Resort Balik Bukit Taman Nasional Bukit Barisan Selatan.

\section{METODE PENELITIAN}

Penelitian dilakukan pada bulan Agustus 2015 di Resort Balik Bukit Taman Nasional Bukit Barisan Selatan. Alat yang digunakan dalam penelitian ini adalah tali plastik, rol meter, cutter, kamera digital, Global Positioning System (GPS), alat pengukur suhu, alat pengukur kelembaban tanah, alat pengukur ketinggian tempat (Altimeter),Binokuler, Luxmeter, alat pengukur ketinggian pohon (Christen-Hypsometer/Haga), alat tulis dan tally sheet. Objek yang diteliti adalah anggrek Eria spp.yang ada di tempat penelitian.

Jenis data yang yang dikumpulkan dalam penelitian ini adalah data primer dan data sekunder. Data primer diperoleh langsung di lapangan dengan menggunakan petak pengamatan. Data primer yang diambil meliputi jumlah anggrek Eria spp., jenis anggrek Eria spp. dan jenis pohon penopangnya di Resort Balik Bukit Taman Nasional Bukit Barisan Selatan. Data sekunder adalah data yang sifatnya mendukung data primer, diperoleh melalui studi literatur, hasil penelitian terdahulu, dan dinas/instansi terkait. Data sekunder yang diambil meliputi karakteristik lokasi, ketinggian tempat, kelembaban tanah, kondisi iklim dan informasi dari masyarakat. 


\section{HASIL DAN PEMBAHASAN}

\section{Populasi dan Pola Penyebaran Anggrek Eria spp.}

Hasil penelitian menunjukkan bahwa di Resort Balik Bukit Taman Nasional Bukit Barisan Selatan (TNBBS) Kabupaten Lampung Barat terdapat 10 jenis anggrek Eria. Populasi dan pola penyebaran anggrek Eria tersebut disajikan dalam Tabel 1.

Tabel 1. Populasi dan pola penyebaran anggrek Eria spp. yang ditemukan di Resort Balik Bukit Taman Nasional Bukit Barisan Selatan.

\begin{tabular}{clcccl}
\hline No. & $\begin{array}{c}\text { Populasi anggrek } \\
\text { Eria spp. }\end{array}$ & $\begin{array}{c}\text { Kerapatan } \\
\text { (individu/ha) }\end{array}$ & Frekuensi & $\frac{v}{m}$ & $\begin{array}{c}\text { Pola } \\
\text { Penyebaran }\end{array}$ \\
\hline 1. & Eria discolor & 3,33 & 0,04 & 4,38 & Bergerombol \\
2. & Eria erecta & 14,72 & 0,17 & 4,29 & Bergerombol \\
3. & Eria flavescens & 8,33 & 0,09 & 6,5 & Bergerombol \\
4. & Eria iridifolia & 22,50 & 0,2 & 12,09 & Bergerombol \\
5. & Eria javanica & 4,4 & 0,03 & 5,29 & Bergerombol \\
6. & Eria junghunii & 1,67 & 0,06 & 0.83 & Seragam \\
7. & Eria mucronata & 1,11 & 0,03 & 1,75 & Bergerombol \\
8. & Eria oblitterata & 1,94 & 0,04 & 2 & Bergerombol \\
9. & Eria retusa & 3,06 & 0,04 & 4,5 & Bergerombol \\
10. & Eria robusta & 1,11 & 0,04 & 1 & Acak \\
\hline
\end{tabular}

Hasil pengamatan menunjukkan bahwa anggrek jenis E. iridifolia ditemukan paling banyak, yaitu sebesar 22,50 individu/ha, diikuti oleh jenis E. erecta sebesar 14, 72 individu/ha dan jenis E. flavescens sebesar 8,33 individu/ha. Sedangkan jenis lain yaitu E. discolor, E. javanica, Eria junghunii, E. mucronata, E. oblitterata, E. retusa, E. robustamemiliki kerapatan sebesar $1-4$ individu/ha.

\section{Jenis Pohon Penopang Anggrek Eria spp.}

Anggrek Eria spp. merupakan anggrek epifit yang berasosiasi dengan pohon sebagai penopang atau tempat tumbuh anggrek tersebut. Jenis-jenis pohon penopang yang merupakan tempat menempel berbagai jenis anggrek Eria di Resort Balik Bukit TNBBS disajikan dalam Tabel 2. 
Tabel 2. Jenis anggrek Eria dan jenis pohon yang menjadi penopangnya di Resort Balik Bukit Tanam Nasional Bukit Barisan Selatan Kabupaten Lampung Barat.

\begin{tabular}{|c|c|c|c|}
\hline No. & Jenis anggrek & No. & Nama pohon penopang \\
\hline \multirow[t]{3}{*}{1.} & Eria discolor & 1. & Manggisan (Garcinia nervosa) \\
\hline & & 2. & Pasang (Quercus sondaica) \\
\hline & & 3. & Bamban (Donax canniformis) \\
\hline \multirow[t]{8}{*}{2.} & Eria erecta & 1. & Marak (Macaranga macrastachys) \\
\hline & & 2. & Simpur (Dillenia excelsa) \\
\hline & & 3. & Lana daun kecil (Dehaasia microsepala) \\
\hline & & 4. & Medang (Litseaangulata) \\
\hline & & 5. & Kulut (Aglaia argentea) \\
\hline & & 6. & Pasang (Quercus sondaica) \\
\hline & & 7. & Tenam (Anisoptera marginata) \\
\hline & & 8. & Rengas (Gluta renghas) \\
\hline \multirow[t]{6}{*}{3.} & Eria flavescens & 1. & Langok (Dysoxylum sp.) \\
\hline & & 2. & Jengkol hutan (Pithecellobium jiringa) \\
\hline & & 3. & Kongkih merah (Aphanamixis grandifolia) \\
\hline & & 4. & Simpur (Dillenia excelsa) \\
\hline & & 5. & Geok (Popowia pisocarpa) \\
\hline & & 6. & Pasang (Quercus sondaica) \\
\hline \multirow[t]{8}{*}{4.} & Eria iridifolia & 1. & Lana daun kecil (Dehaasia microsepala) \\
\hline & & 2. & Kulut (Aglaia argentea) \\
\hline & & 3. & Manggisan (Garcinia nervosa) \\
\hline & & 4. & Geok (Popowia pisocarpa) \\
\hline & & 5. & Pasang (Quercus sondaica) \\
\hline & & 6. & Balem (Dipterocarpus palembanicus) \\
\hline & & 7. & Tenam (Anisoptera marginata) \\
\hline & & 8. & Rengas (Gluta renghas) \\
\hline \multirow[t]{2}{*}{5.} & Eria javanica & 1. & Lana daun kecil (Dehaasia microsepala) \\
\hline & & 2. & Geok (Popowia pisocarpa) \\
\hline \multirow[t]{4}{*}{6.} & Eria junghunii & 1. & Lana daun kecil (Dehaasia microsepala) \\
\hline & & 2. & Geok (Popowia pisocarpa) \\
\hline & & 3. & Lapan (Vitex quinata) \\
\hline & & 4. & Jambuan (Eugenia sp.) \\
\hline \multirow[t]{3}{*}{7.} & Eria mucronata & 1. & Pasang (Quercus sondaica) \\
\hline & & 2. & Lapan (Vitex quinata) \\
\hline & & 3. & Jambuan (Eugenia sp.) \\
\hline \multirow[t]{4}{*}{8.} & Eria oblitterata & 1. & Kongkih merah (Aphanamixis grandifolia) \\
\hline & & 2. & Medang (Litseaangulata) \\
\hline & & 3. & Kulut (Aglaia argentea) \\
\hline & & 4. & Pasang (Quercus sondaica) \\
\hline \multirow[t]{3}{*}{9.} & Eria retusa & 1. & Konki (Pometia pinnata) \\
\hline & & 2. & Geok (Popowia pisocarpa) \\
\hline & & 3. & Balem (Dipterocarpus palembanicus) \\
\hline \multirow[t]{2}{*}{10.} & Eria robusta & 1. & Pasang (Quercus sondaica) \\
\hline & & 2. & Bamban (Donax canniformis) \\
\hline
\end{tabular}


Dari Tabel 2, jenis pohon pasang (Quercus sondaica) dan geok (Popowia pisocarpa) merupakan jenis pohon penopang yang cocok sebagai inang/tempat tumbuh anggrek Eria spp. Hampir semua jenis anggrek Eria yaitu E. discolor, E. erecta, E. flavescens, E. iridifolia, E. mucronata, E. oblitterata, E robusta berasosiasi dengan pohon pasang (Quercus sondaica) dan jenis angggrek E. erecta, E. flavescens, E. iridifolia, E. javanica, E. junghunii, E. retusa berasosiasi dengan pohon geok (Popowia pisocarpa).

\section{Data Kondisi Kesehatan dan Kondisi Lingkungan di Kawasan Resort Balik Bukit Taman Nasional Bukit Barisan Selatan}

Adapun kondisi lingkungan di Kawasan Resort Balik Bukit Taman Nasional Bukit Barisan Selatan yang meliputi ketinggian tempat, suhu udara, kelembapan udara dan intensitas radiasi matahari adalah sebagaimana disajikan pada Tabel 3.

Tabel 3. Data kondisi lingkungan tempat tumbuh anggrek Eria spp. di Kawasan Resort Balik Bukit Taman Nasional Bukit Barisan Selatan.

\begin{tabular}{clcccc}
\hline No. & Jenis anggrek & $\begin{array}{c}\text { Ketinggian } \\
\text { tempat } \\
(\mathrm{m} \mathrm{dpl})\end{array}$ & $\begin{array}{c}\text { Suhu udara } \\
\left({ }^{\circ} \mathrm{C}\right)\end{array}$ & $\begin{array}{c}\text { Kelembapan } \\
\text { udara }(\%)\end{array}$ & $\begin{array}{c}\text { Intensitas } \\
\text { radiasi } \\
\text { matahari (lux })\end{array}$ \\
\hline 1. & Eria discolor & $678-764$ & $26,1-28,7$ & $80-89$ & $245-817$ \\
2. & Eria erecta & $630-818$ & $25,1-31,2$ & $77-99$ & $211-1.817$ \\
3. & Eria flavescens & $685-831$ & $25,3-32,4$ & $74-81$ & $517-1.999$ \\
4. & Eria iridifolia & $626-733$ & $25,2-33,1$ & $74-89$ & $165-1.200$ \\
5. & Eria javanica & $678-752$ & $27,7-28,7$ & 80 & $708-1.200$ \\
6. & Eria junghunii & $620-733$ & $25,3-28,7$ & $77-91$ & $245-964$ \\
7. & Eria mucronata & $615-726$ & $25,8-29,3$ & $78-99$ & $265-397$ \\
8. & Eria oblitterata & $620-783$ & $25,3-31,2$ & $78-91$ & $446-964$ \\
9. & Eria retusa & $630-783$ & $27,5-29,8$ & $79-85$ & $378-572$ \\
10. & Eria robusta & $690-787$ & $25,6-30,7$ & $77-99$ & $290-1.743$ \\
\hline
\end{tabular}

Dari Tabel 3, anggrek Eria spp. yang ditemukan di lokasi penelitian masuk dalam kriteria sehat dan cocok tumbuh di ketinggian $600-800 \mathrm{~m}$ dpl dengan suhu $25-32{ }^{\circ} \mathrm{C}$, kelembapan udara 70-90\% dan intensitas radiasi matahari dikisaran 300-1.200 lux.

\section{Kondisi Kesehatan Anggrek Eria spp. di Kawasan Resort Balik Bukit Taman Nasional Bukit Barisan Selatan}

Pada umumnya 80-90\% anggrek Eria spp. yang ditemukan di lokasi penelitian dalam kondisi sehat. Akan tetapi, ada sebagian kecil yaitu 10-20\% ditemukan dalam kondisi daun layu, batang daun mengering/busuk dan bunga yang gugur. Kondisi ini ditunjukkan pada pada Gambar 1 dan Gambar 2.

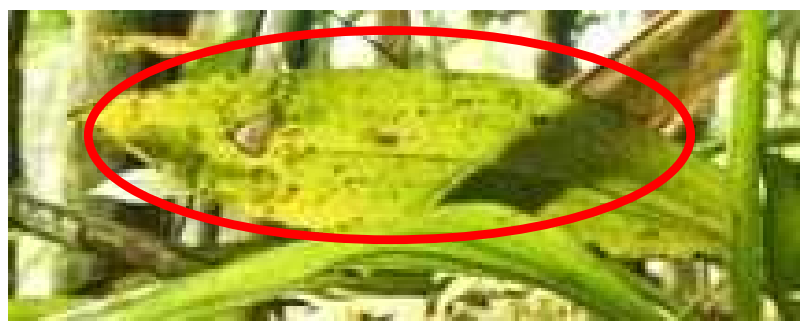

Gambar 1. Kondisi daun anggrek Eria javanica yang tidak sehat (gambar diambil oleh Efendi, Agustus 2015 


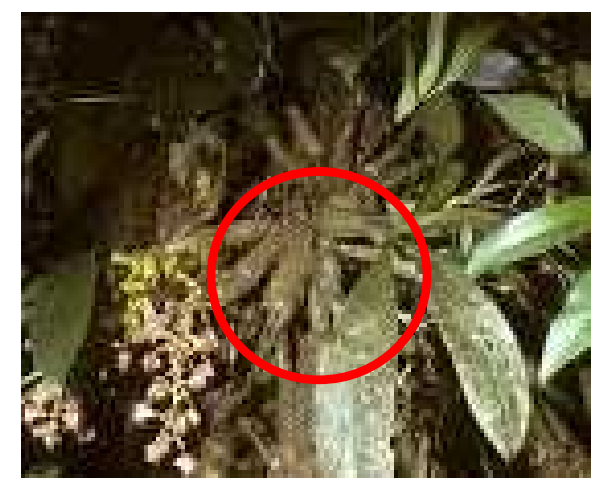

Gambar 2. Kondisi umbi Eria flavescens yang tidak sehat (gambar diambil oleh Efendi, Agustus 2015)

\section{Deskripsi Anggrek Eria spp. di Kawasan Resort Balik Bukit Taman Nasional Bukit Barisan Selatan}

\section{Eria discolor}

Anggrek E. discolor merupakan anggrek epifit yang tumbuh menjalar. Akar rimpang anggrek tersebut bersifat keras dan kaku, membentuk umbi semu dengan jarak antar dua umbi $20-50 \mathrm{~cm}$. Umbi semunya menggembung di bagian tengah dan meruncing di kedua ujungnya, panjang $15 \mathrm{~cm}$, setiap umbi memiliki 4-6 helai daun. Daun berbentuk lanset, berukuran panjang $10 \mathrm{~cm}$ dan lebar $2,5 \mathrm{~cm}$, dan ujungnya terbelah dua. Perbungaan anggrek ini tumbuh di ketiak daun, memanjang secara bertahap hingga $8 \mathrm{~cm}$, bunganya mekar tidak serempak dan hanya $1-2$ kumtum yang mekar bersamaan, serta memiliki daun penumpu. Pada saat bunga mekar ukurannya berdiameter $1,7 \mathrm{~cm}$. Perhiasan bunganya berwarna kuning dan di bagian luarnya ditumbuhi bulu-bulu halus berwarna putih. Bibir bunga pada anggrek ini tidak bulat penuh tapi berbentuk segi lima, tidak bercuping, berwarna coklat tua dengan tonjolan kuning di tengahnya.

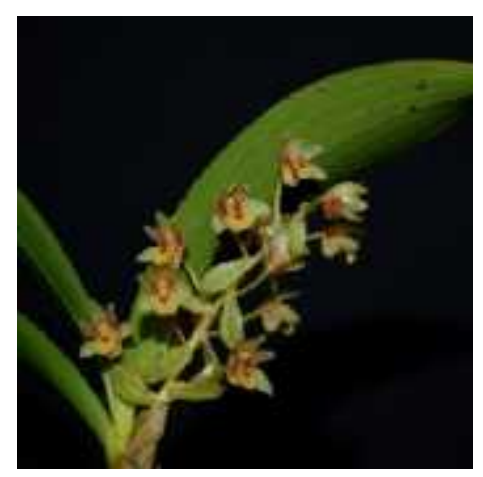

Gambar 3. Eria discolor (gambar diambil dari www.kebunbibit.id, September 2015)

\section{Eria erecta}

Anggrek E. erecta merupakan anggrek epifit. Anggrek tersebut memiliki 14-16 helai daun yang tersusun dalam dua deretan dengan bentuk memanjang. Bunganya kecil dan berumpun banyak dengan warna yang beragam dari putih, merah muda, hingga keunguan. 


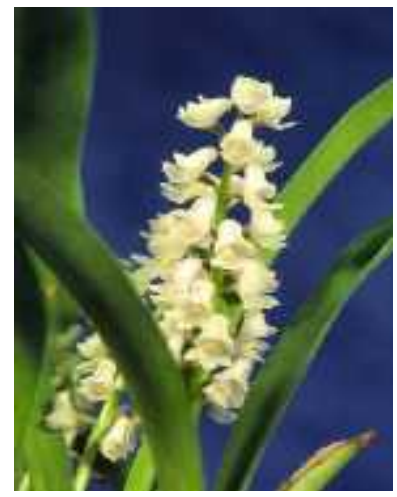

A

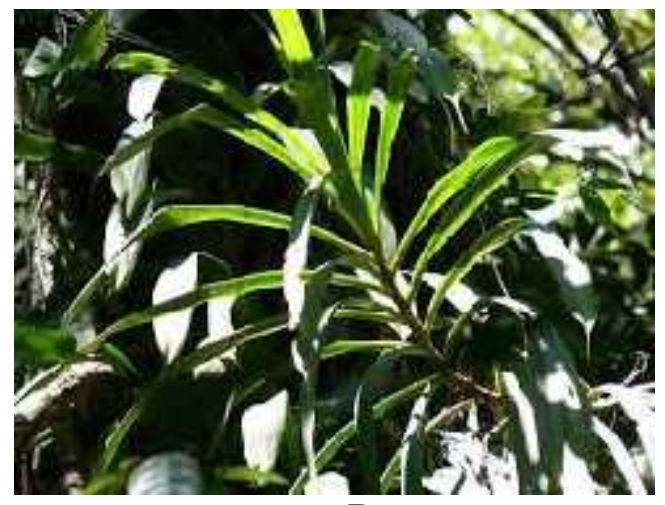

B

Gambar 4. A. Eria erecta (gambar diambil dari www.orchidboard.com, November 2008)

B. Eria erecta (gambar diambil oleh Albarkati, Agustus 2015)

\section{Eria flavescens}

Anggrek E. flavescens merupakan anggrek epifit yang tumbuh simpodial. Anggrek tersebut memiliki umbi semu berukuran panjang $20 \mathrm{~cm}$ dan tebal hingga $2 \mathrm{~cm}$. Daunnya berjumlah 2-4 helai, muncul dari ujung umbi semu, berukuran lebar $30 \mathrm{~cm}$ dan panjang 50 $\mathrm{cm}$ tetapi anggrek E. flavescens yang hidup di dataran rendah berukuran lebih kecil. Perbungaannya muncul di ujung umbi semu yang berdaun, panjangnya $10-15 \mathrm{~cm}$, mendukung 10-20 kuntum bunga, tersusun dalam bentuk tandan. Hampir seluruh permukaan bunganya ditumbuhi bulu halus berwarna coklat. Pada saat bunga anggrek ini mekar penuh berukuran lebar $1,25 \mathrm{~cm}$, beraroma asam menyengat, seluruh perhiasan bunganya berwarna dasar kuning pucat kehijauan dan bergaris-garis merah hati. Setiap bunga memiliki daun pelindung yang berwarna hijau muda, terletak di pangkal gagang bunga. Kelopak punggung anggrek ini berbentuk bulat telur, berukuran panjang $12 \mathrm{~mm}$ dan lebar $5 \mathrm{~mm}$, kelopak sampingnya membentuk dagu (mentum), lebar di bagian dasar, berukuran panjang 13,5 mm dan lebar $6 \mathrm{~mm}$. Mahkotanya berukuran lebih sempit berukuran panjang $10 \mathrm{~mm}$ dan lebar 4 mm. Bibir bunga anggrek E. flavescens didominasi warna merah hati, dan ujungnya menekuk ke bawah. Anggrek E. flavescens merupakan jenis anggrek dataran tinggi.

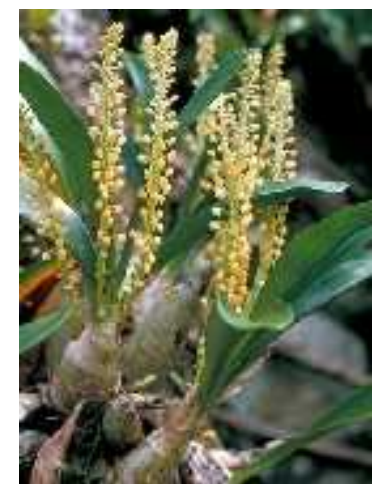

Gambar 5. Eria flavescens (gambar diambil dari www.keys.trin.org.au, Desember 2014)

\section{Eria iridifolia}

Anggrek E. iridifolia merupakan anggrek epifit yang tumbuh simpodial tapi sekilas mirip dengan anggrek yang tumbuh monopodial. Daunnya berjumlah hingga 14 helai yang tersusun dalam 2 deretan, berukuran panjang $50 \mathrm{~cm}$ dan lebar $4 \mathrm{~cm}$. Perbungaan anggrek ini muncul di ujung batang dan tumbuh di ketiak daun, tersusun dalam bentuk tandan yang terdiri dari 80-100 kuntum. Bunga dari anggrek E. iridifolia memiliki perhiasan bunga yang saling 
memencar lebar, pada saat mekar berdiameter $7 \mathrm{~mm}$, berwarna dasar kuning dan didominasi warna merah hati. Kelopaknya berbintik-bintik merah dan permukaan luarnya berbulu halus. Bibir bunga menonjol ke depan, berwarna putih dan ujungnya membelah dua seperti gigi.

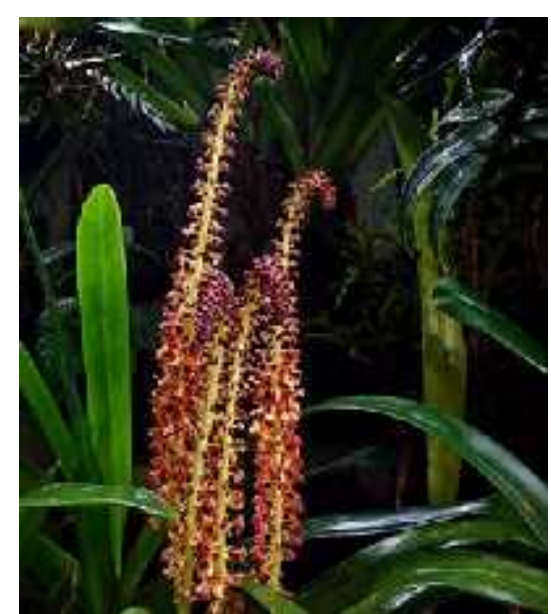

A

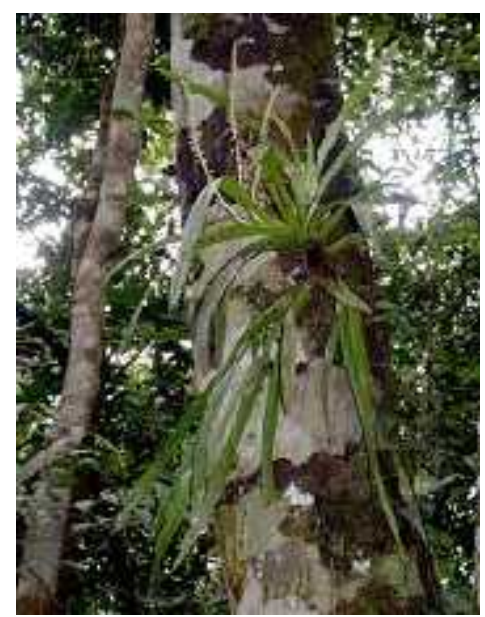

B

Gambar 6. A. Eria iridifolia (gambar diambil oleh Sutanto, Agustus 2014) B. Eria iridifolia (gambar diambil oleh Albarkati, Agustus 2015)

\section{Eria javanica}

Anggrek E. javanica memiliki batang yang langsing di bagian pangkal dan membesar di bagian ujung dengan panjang mencapai $20 \mathrm{~cm}$. Daun berbentuk seperti pedang, terdapat di ujung batang berbentuk melengkung dan agak sempit dengan panjang sekitar $15 \mathrm{~cm}$. Tandan bunga keluar dari ketiak daun atau ujung batang dengan panjang $10 \mathrm{~cm}$ dan setiap tandan mempunyai 20-30 kuntum bunga. Bunganya kecil dengan warna yang beraneka ragam, dari putih, kuning susu, sampai lembayung. Kelopak dan mahkota bunga berbentuk mata tombak berwarna putih atau kuning pucat. Bibir bunga berbentuk pita, bertajuk tiga dengan bagian samping tumpul, tegak, dan bagian tengahnya panjang beralur kuning.

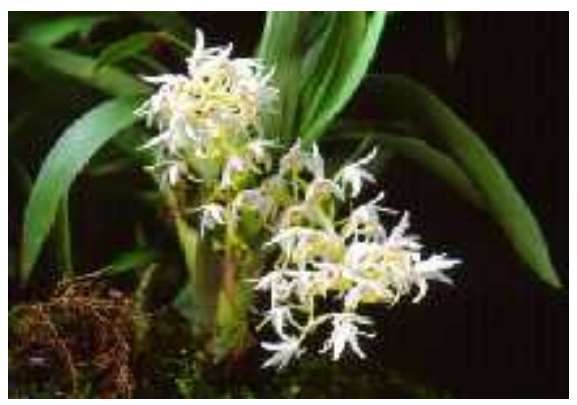

Gambar 7. Eria javanica (gambar diambil oleh Wardhana, Agustus 2012)

\section{Eria junghunii}

Anggrek E. junghunii merupakan anggrek epifit yang tumbuh simpodial. Daunnya berjumlah 2-4 helai dengan bentuk lanset. Anggrek ini memiliki bunga yang merumpun dengan bentuk memanjang pada kelopaknya, tumbuh dari pangkal batang. 


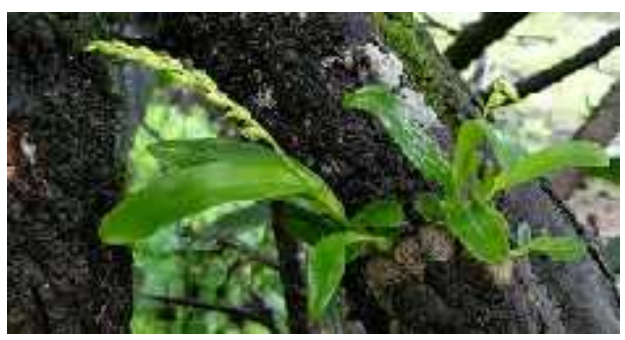

Gambar 8. Eria junghunii (gambar diambil dari Amazonaws.com, Agustus 2015)

\section{Eria mucronata}

Anggrek E. mucronata merupakan anggrek epifit. Batangnya menggantung, panjangnya mencapai $1 \mathrm{~m}$, berdaging, menggalah, dan ujung batangnya pipih. Daun dari anggrek ini berbentuk lanset, lancip, berdaging dan liat, panjang 5,5-12 cm, lebar di bagian tengahnya 6-10 mm. Perbungaannya tumbuh di lateral atau di samping daun, berukuranpendek, biasanya mendukung 2 bunga, daun pelindung bunga berwarna marah. Bunga anggrek ini berukuran relatif besar tetapi tidak membuka penuh pada saat mekar, berwarna putih kekuningan, daun kelopak bagian dorsal melonjong dan tumpul, panjang 1,9 $\mathrm{cm}$. Pada bagian pangkal kelopak melebar membentuk mentum yang ujungnya tumpul, panjang 1,2 cm. Daun mahkota merbentuk bulat telur, rompang (truncate) dan berembang (apiculate), panjang 1,9 cm. Bibir bunga anggrek E. mucronata berukuranpendek, dibagian pangkal berbentuk seperti ginjal, di bagian tengah bercuping 3, cuping samping tegak dan berbentuk setengah lingkaran, cuping tengah berukuran lebih kecil dan mempunyai anak cuping, pada helaian cupingtengah terdapat tunas yang memanjang dari pangkal ke bagian ujung, panjang bibir bunganya $1,1 \mathrm{~cm}$ dan lebar $1,5 \mathrm{~cm}$.

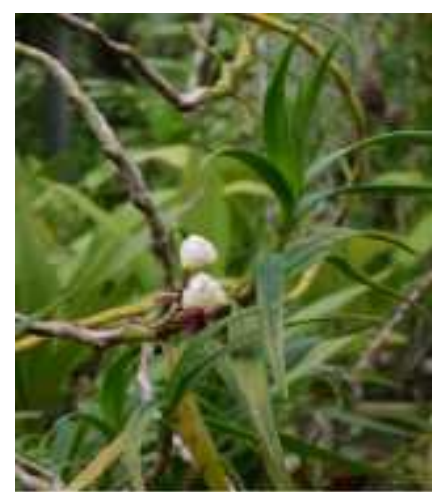

Gambar 9. Eria mucronata (gambar diambil oleh Puspitaningtyas, Juni 2002)

\section{Eria oblitterata}

Anggrek E. oblitterata merupakan anggrek epifit yang tumbuh merumpun dan memiliki tinggi tanaman mencapai $65 \mathrm{~cm}$. Anggrek ini memiliki daun berbentuk memanjang dengan ujung runcing yang tersusun berselang-seling berhadapan, panjang $20 \mathrm{~cm}$ dan lebar $1,9 \mathrm{~cm}$. Perbungaannya muncul di ujung batang (terminal), berbentuk tandan. Bunganya berjumlah banyak berukuran kecil dengan diameter $0,7 \mathrm{~cm}$. Perhiasan bunganya berwarna hijau kekuningan, polos tanpa bercak-bercak.Bibir bunga anggrek E. oblitterata berwarna putih di bagian garis tengahnya dan cuping samping berwarna titik-titik kemerahan. 


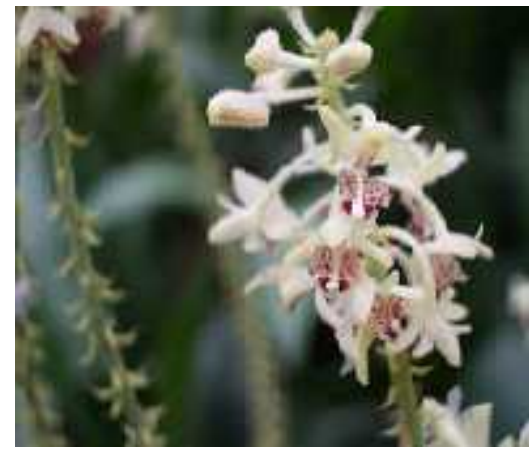

A

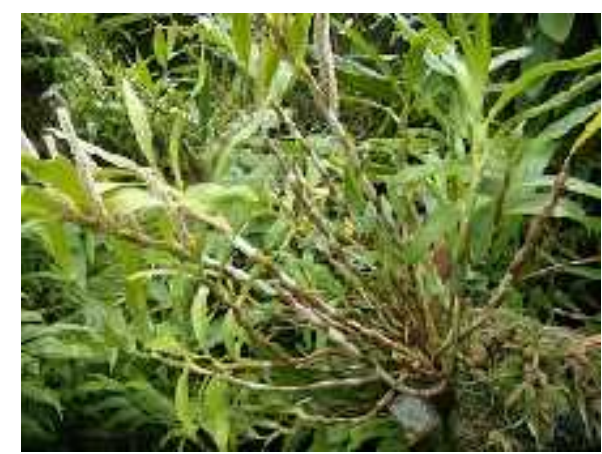

B

Gambar 10. A. Eria oblitterata (gambar diambil dari www.flickrhivemind.net, Februari 2015) B. Eria oblitterata (gambar diambil oleh Albarkati, Agustus 2015)

\section{Eria retusa}

Anggrek E. retusa merupakan anggrek epifit yang tumbuh simpodial. Umbi semunya berbentuk bulat hingga oval, berdiameter $1-1,5 \mathrm{~cm}$. Rata-rata memiliki satu hingga dua daun pada setiap ujung umbinya. Daun dari anggrek ini tebal berdaging, berbentuk lanset memanjang, berukuran panjang $5 \mathrm{~cm}$ hingga $11 \mathrm{~cm}$, dan lebarnya 0,5-1 cm. Perbungaan anggrek E. retusa tersusun dalam bentuk tandan, tumbuh di ujung umbi. Tangkai perbungaannya memiliki panjang 1,8 cm, jumlah bunganya sekitar 12-16 kuntum. Bunga anggrek ini berwarna kuning pucat, kelopaknya berbentuk triangular, mahkota berbentuk lanset dengan ukuran panjang yang hampir sama dengan kelopaknya. Bibir bunganya berbentuk bulat telur dan seluruh permukaan bunganya berbulu.

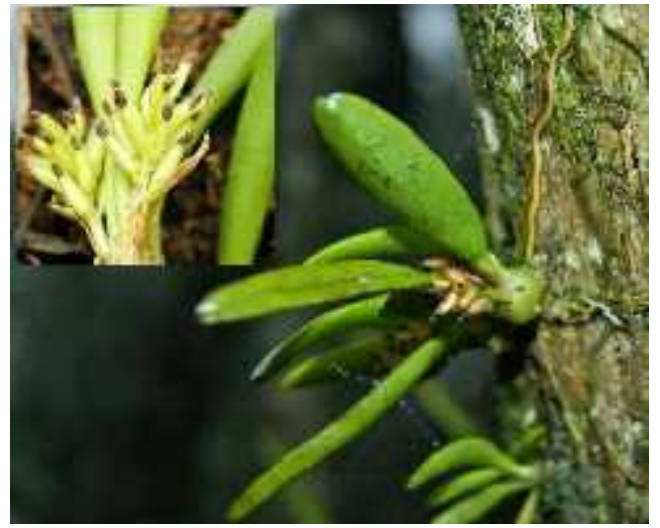

A

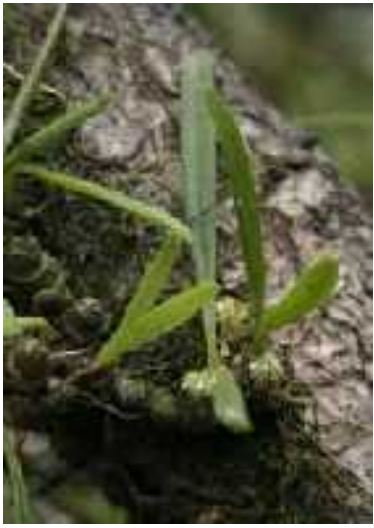

B

Gambar 11. A. Eria retusa (gambar diambil oleh Wardhana, Agustus 2012) B. Eria retusa (gambar diambil oleh Albarkati, Agustus 2015)

\section{Eria robusta}

Anggrek E. robusta merupakan anggrek epifit yang tumbuh simpodial.Anngrek ini memiliki umbi semu yang tak tampak jelas. Daunnya berjumlah dua pada setiap umbi, berbentuk pita atau lanset, berujung runcing, berukuran panjang $40 \mathrm{~cm}$ dan lebar $3,5 \mathrm{~cm}$. Perbungaan dari anggrek ini tersusun rapat dalam bentuk tandan, jumlah bunganya lebih dari 50 kumtum. Bunganya pada saat mekar berdiameter $5 \mathrm{~mm}$, perhiasan bunga berwarna dasar kuning di bagian tepinya dan coklat kemerahan di bagian pangkalnya. Kelopak samping dari anggrek ini berbentuk segitiga lebar, menyerupai sayap yang mengembang. Mahkotanya 
kecil, berbentuk seperti pita yang memanjang dan terbuka ke samping. Bibir bunganya berwarna kuning, ujungnya seperti segitiga meruncing dan menekuk ke bawah.

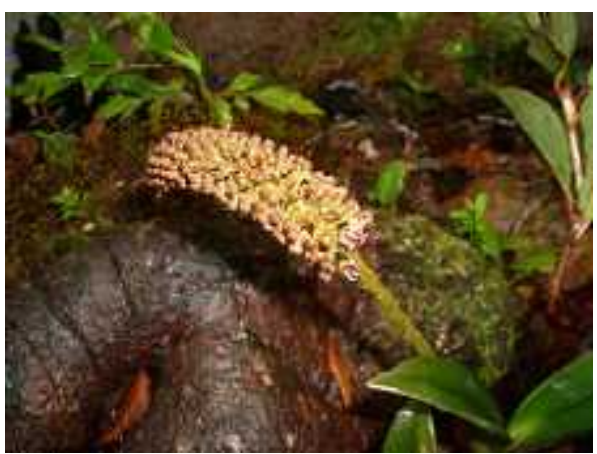

A

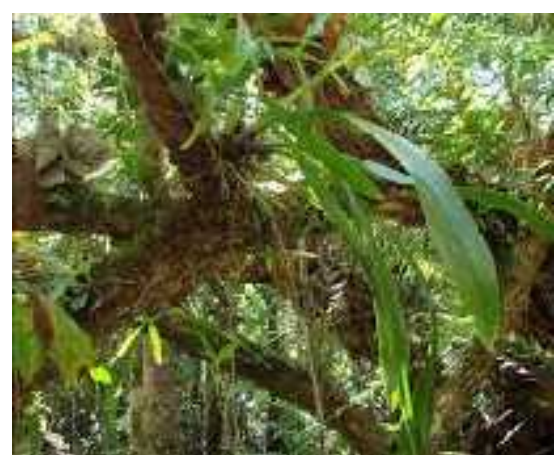

B

Gambar 12. A. Eria robusta (gambar diambil dari www.flickrhivemind.net, Februari 2015)

B. Eria robusta (gambar diambil oleh Albarkati, Agustus 2015)

\section{Pembahasan}

Dari hasil pengamatan pada 90 petak di Resort Balik Bukit Taman Nasional Bukit Barisan Selatan ditemukan 10 jenis anggrek Eria dengan keseluruhan jumlah 237 individu yang berasosiasi dengan 18 jenis pohon penopang. Anggrek Eria spp. merupakan anggrek epifit, hidup dengan menempel/berasosiasi pada batang pohon.

Dari hasil penelitian dapat diketahui bahwa kawasan Resort Balik Bukit Taman Nasional Bukit Barisan Selatan merupakan salah satu habitat yang cocok untuk tumbuhan anggrek epifit. Tumbuhan epifit adalah tumbuhan yang hidupnya menempel pada tumbuhan lain sebagai penopang, tidak berakar pada tanah, berukuran lebih kecil dari tumbuhan penopang atau inang, tetapi tidak merugikan terhadap tumbuhan penopang. Kebutuhan zat hara tumbuhan epifit tidak mengandalkan pada pohon inangnya, dengan demikian epifit dibedakan dari tumbuhan parasit (Suwila, 2015).

Kawasan Resort Balik Bukit Taman Nasional Bukit Barisan Selatan memiliki kelembapan yang tinggi berkisar antara 74-99 \% dengan suhu yang relatif rendah yaitu $25,1-33,1{ }^{\circ} \mathrm{C}$, sehingga sangat memungkinkan tumbuhan anggrek dapat tumbuh dan berkembang dengan sangat baik. Menurut Iswanto (2002 dikutip oleh Hasanuddin 2009), pada umumnya anggrek membutuhkan suhu maksimum sekitar $28{ }^{\circ} \mathrm{C}$ dan suhu minimum sekitar $15^{\circ} \mathrm{C}$. Beberapa spesies anggrek alam yang tumbuh di daerah pegunungan hidup dan berkembang pada suhu rendah, yakni sekitar 5-10 ${ }^{\circ} \mathrm{C}$. Ditinjau dari aspek suhu, anggrek terbagi atas tiga jenis yaitu: (1) Anggrek suhu dingin adalah anggrek yang tumbuh di daerah pegunungan di ketinggian $2000-4000 \mathrm{~m}$ dpl. Anggrek jenis ini tumbuh baik pada suhu $15-$ $2{ }^{\circ} \mathrm{C}$ saat siang hari dan $10-13{ }^{\circ} \mathrm{C}$ saat malam hari; (2) Anggrek suhu sedang adalah anggrek yang tumbuh di daerah yang mempunyai ketinggian antara $750-2000 \mathrm{~m}$ dpl. Anggrek jenis ini tumbuh baik pada suhu $21-32{ }^{\circ} \mathrm{C}$ saat siang hari dan $13-18{ }^{\circ} \mathrm{C}$ saat malam hari; (3) Anggrek suhu panas adalah anggrek yang tumbuh di dataran rendah yang memiliki ketinggian antara $0-750 \mathrm{~m} \mathrm{dpl}$. Anggrek jenis ini tumbuh baik pada suhu $26-35^{\circ} \mathrm{C}$ saat siang hari dan $18-24^{\circ} \mathrm{C}$ saat malam hari.

Berdasarkan pengamatan di lokasi penelitian didapatkan hasil bahwa anggrek Eria spp. lebih cenderung menempel pada pohon penopang yang memiliki kulit tebal, beralur maupun berserabut dan memiliki kulit keras. Sesuai dengan pendapat Ewusie (1990 dikutip oleh Nawawi 2014) bahwa kulit tumbuhan penopang yang mempunyai alur dan celah akan menyebabkan epifit tumbuh dengan subur, sedangkan kulit tumbuhan penopang yang agak 
licin akan menyebabkan epifit sulit untuk melekat dan tumbuh pada penopang tersebut. Habitus epifit lebih cenderung berada pada tumbuhan penopang yang berkulit keras karena lebih mampu mempertahankan ikatan akar yang menempel pada kulit pohon sehingga dapat mempertahankan keberadaan epefit di tumbuhan tersebut. Menurut Puspaningtyas (2003) anggrek ini tumbuh pada percabangan utama pohon besar.

Penyebaran anggrek Eria spp. di Resort Balik Bukit banyak ditemukan di ketinggian $600-700 \mathrm{~m}$ dpl dengan suhu $26-28{ }^{\circ} \mathrm{C}$. Hal ini diduga oleh adanya pengaruh faktor fisiografis, tanah dan faktor-faktor iklim serta komposisi jenis vegetasinya. Berdasarkan hasil pengamatan, jenis anggrek Eria yang memiliki tingkat kerapatan tertinggi adalah $E$. iridifolia, jika dibandingkan dengan jenis anggrek Eria yang lain. Hal ini diduga karena kondisi kelembapan yang cukup tinggi dan suhu yang cukup rendah.

Pola penyebaran anggrek Eria spp. di Resort Balik Bukit mencakup ketiga kategori yaitu acak, seragam dan bergerombol. Anggrek yang masuk kedalam kategori distribusi acak yaitu E. robusta. Anggrek yang masuk kedalam kategori distribusi seragam yaitu $E$. junghunii. Sedangkan anggrek yang masuk kedalam kategori bergerombol yaitu E. discolor, E. erecta, E. flavescens, E. iridifolia, E. javanica, E. mucronata, E. oblitterata dan E. retusa.

Distribusi acak terjadi apabila kondisi lingkungan seragam, tidak ada kompetisi yang kuat antar individu anggota populasi dan masing-masing individu tidak melmiliki kecenderungan untuk memisahkan diri. Distribusi seragam terjadi apabila kondisi lingkungan cukup seragam di seluruh area dan ada kompetisi yang kuat antar individu anggota populasi. Kompetisi yang kuat antar individu anggota populasi akan mendorong terjadinya pembagian ruang yang sama. Heddy dkk. (1986 dikutip oleh Indriyanto 2008) memberikan contoh bahwa pada hutan yang lebat, maka pohon yang tinggi hampir mempunyai distribusi seragam. Pohon-pohon dominan di hutan demikian jaraknya teratur karena kompetisi yang sangat kuat untuk mendapatkan cahaya dan unsur hara.

\section{SIMPULAN}

Berdasarkan hasil penelitian, dapat disimpulkan bahwa populasi anggrek Eria spp. ditemukan sebanyak 10 jenis anggrek. Anggrek jenis Eria iridifolia ditemukan paling banyak sebesar 22,50 individu/ha, diikuti oleh jenis E. erecta sebesar 14,72 individu/ha dan jenis E. flavescens sebesar 8,33 individu/ha. Sedangkan jenis lain yaitu E. discolor, E. javanica, E. junghunii, E. mucronata, E. oblitterata, E. retusa, E. Robusta memiliki kerapatan sebesar 1-4 individu/ha. Kondisi kesehatan anggrek 80-90\% ditemukan dalam keadaan sehat dan 10-20\% ditemukan dalam keadaan tidak sehat. Pola penyebaran pada anggrek $E$. discolor, E. erecta, E. flavescens, E. iridifolia, E. javanica, E. mucronata, E. obletterata, dan $E$. retusa masuk kedalam kategori bergerombol. Sedangkan anggrek E. junghunii masuk kedalam kategori seragam dan anggrek E. robusta masuk kedalam kategori acak. 


\section{DAFTAR PUSTAKA}

Amazonaws. 2015. Orchids of India. Diakses pada tanggal 18 Februari 2016 pukul 13.10 WIB.http://amazonaws.com/flickriver-lb-1710691658.us-east-1.elb.groups/ myorchidphotos/pool/interesting.

Balai Besar Taman Nasional Bukit Barisan Selatan. 2009. Keanekaragaman Jenis Flora di Taman Nasional Bukit Barisan Selatan. Diakses pada tanggal 1 Oktober 2014 pukul 10.35 WIB. http//www.tnbbs.org/web/index.php.

Flickr Hive Mind. 2015. Eria Orchids. Diakses pada tanggal 18 Februari 2016 pukul 13.08 WIB.http://flickrhivemind.net/Tags/eria,orchid/Interesting.

Hasanuddin. 2010. Jenis tumbuhan anggrek epifit di Kawasan Cagar Alam Jantho Kabupaten Aceh Besar. Skripsi. Universitas Syiah Kuala Banda Aceh. 49 p.

Indriyanto. 2008. Ekologi Hutan. Buku. PT. Bumi Aksara. Jakarta. 210 p.

Kebun Bibit. 2015. Macam-macam Tanaman Hias. Diakses pada tanggal 18 Februari 2016 pukul 12.41 WIB. https://kebunbibit.id/tanaman/tanaman-hias-bunga/anggrek/anggrekspecies/eria/eria-discolor.html.

Kingii, P. 2014. Australian Tropical Rainforest Orchids. Diakses pada tanggal 18 Februari 2016 pukul 12.49 WIB. http://keys.trin.org.au/key-server/data/08090a09-0d0e-410b860c-020705070e0e/media/Html/pinalia_kingii.htm.

Lembaga Ilmu Pengetahuan Indonesia. 2011. Eksplorasi keanekaragaman tumbuhan anggrek di Kawasan Taman Nasional Bukit Barisan Selatan. Jurnal Konservasi Tumbuhan Tropika. 6(3):13-17.

Nawawi. 2014. Jenis-jenis anggrek epifit pada Kawasan Hutan Bremi Distrik Manokwari Utara. Jurnal Biodiversitas. 1(2):7-10.

Orchidboard. 2008. What's an Orchids Name. Diakses pada tanggal 18 Februari 2016 pukul 12.46 WIB. http://www.orchidboard.com/orchid-naming-explained.

Puspitaningtyas, D. M. 2005. Studi keragaman anggrek di Cagar Alam Gunung Simpang. Jurnal Biodiversitas. 6(2):1-5.

Puspitaningtyas, D. M., Mursidati, Sofi., Sutrisno., Asikin, dan Jauhari. 2003. Anggrek Alam di Kawasan Konservasi Pulau Jawa. Buku. Pusat Konservasi Tumbuhan Kebun Raya Bogor-Lembaga Ilmu Pengetahuan Indonesia (LIPI). Bogor. 167 p.

Sutanto, J. 2014. Spesies Anggrek. Diakses pada tanggal 18 Februari 2016 pukul 12.57 WIB. http://www.instagramobi.com/sutantojimmy.

Suwila, M. T. 2015. Identifikasi tumbuhan epifit berdasarkan ciri morfologi dan anatomi batang di Hutan Perhutani sub BKPH Kedunggala, Sonde dan Natah. Jurnal Florea. 2(1): $1-2$.

Wardana, H. 2012. Anggrek Indonesia. Diakses pada tanggal 18 Februari 2016 pukul 13.03 WIB. http://www.kompasiana.com/wardhanahendra/seperti-manusia-tumbuhan-inijuga-selektif-memilih-teman-hidup_55d6ed43ac92732709c43ce0. 